\title{
Evaluation of bone, nutrition, and physical function in Shorinji Kempo athletes
}

\author{
This article was published in the following Dove Press journal: \\ Open Access Journal of Sports Medicine \\ 7 September 2012 \\ Number of times this article has been viewed
}

\author{
Sachiko Sumida ${ }^{1,2}$ \\ Jun Iwamoto 3 \\ Naoto Kamide ${ }^{4}$ \\ Toshiro Otani ${ }^{1,3,5}$ \\ 'Graduate School of Health \\ Management, Keio University, ${ }^{2}$ Sports \\ Medicine Research Center, Keio \\ University, Kanawaga; ${ }^{3}$ nstitute for \\ Integrated Sports Medicine, School \\ of Medicine, Keio University, Tokyo, \\ ${ }^{4}$ School of Allied Health Sciences, \\ Kitasato University, Kanagawa, \\ ${ }^{5}$ Faculty of Nursing and Medical Care, \\ Keio University, Kanawaga, Japan
}

\begin{abstract}
The objectives of this study were to reveal the proportion of Shorinji Kempo athletes who had suffered fractures related to sports activities, and to evaluate bone mass, bone turnover, nutritional status, and physical function in these athletes. A medical examination was carried out for 16 Shorinji Kempo collegiate athletes. Seven athletes (43.8\%) had experienced a sportsrelated traumatic fracture during Shorinji Kempo practice. Four athletes (25.0\%) had a lower speed of sound ( $\%$ young adult mean $<100 \%$ ), and five athletes $(31.3 \%)$ had higher levels of urinary cross-linked $\mathrm{N}$-terminal telopeptides of type 1 collagen (a bone turnover marker) than the age-adjusted standard values. All the athletes had a lower daily calcium intake than the adequate intake, 12 (75.0\%) had a lower daily vitamin D intake, and 15 (93.8\%) had a lower daily vitamin K intake. Significant positive correlations were found between the vertical jump height, and the daily energy, and protein intakes. Results suggest that fractures are a common injury in Shorinji Kempo athletes, and that some Shorinji Kempo athletes need to improve their bone mass, bone metabolism, and nutritional status in order to strengthen bone and improve physical function.
\end{abstract}

Keywords: medical checkup, Shorinji Kempo, fracture, nutrition; physical function

\section{Background}

Shorinji Kempo derives its philosophy from ancient Buddhism, and its basic techniques from old Chinese martial arts. Shorinji Kempo was established in Japan in 1947 by Doshin So as a system for self-improvement and training based on Shaolin kung fu. The training methods are based on the philosophical principles that "spirit and body are not separable," and of "train both body and spirit." Following from this, Shorinji Kempo has been known to have the three benefits of "self-defense and training," "mental training," and "promoting health."

Shorinji Kempo has many skills in its set of defense techniques, but the demonstration known as "embu," is the most common. It is usually performed bare-handed and bare-footed, by two persons called "kumi-embu." During the embu, first one person attacks while the other defends, and then the roles are reversed, and the technique is immediately repeated.

There are two classes of techniques in Shorinji Kempo activities, called the "Goho" and the "Juho." The Goho techniques are generally considered to be the 'hard' techniques within Shorinji Kempo. Goho techniques involve the use of body movement to avoid an attack, blocks to deflect a punch or kick, and counter strikes to prevent further attacks. The blocks do not meet the force of the attack with force but instead, deflect the blow, or are used as a cover to protect the body. Conversely, the Juho 
techniques use movement to unbalance the attacker, and to take advantage of the momentum of the attack, and they are considered to be the 'soft' techniques within Shorinji Kempo. Juho techniques are applied when a person is grasped or pinned by an attacker, and consist of throws, locks and pins, and elusive moves. Scoring of both Goho and Juho takes into consideration attack, and also, defensive gestures, and counterattack. Attitude and manner are also very important and are taken into consideration when scoring.

Shorinji Kempo is practiced at 2900 "doin" (practice locations) and branches in 33 countries worldwide. Given that lacerations, contusions, concussions, facial fractures, fractures, and limb dislocations are common injuries among Karate athletes, ${ }^{1}$ the incidence of fractures among Shorinji Kempo athletes is expected to be high as well.

Calcium, vitamin $\mathrm{D}$, and vitamin $\mathrm{K}$ are important elements in the maintenance of bone health. ${ }^{2}$ Vitamin $\mathrm{K}$ insufficiency leads to a deterioration of bone quality, resulting in an increased risk of fractures. ${ }^{3,4}$ Vitamin D insufficiency stimulates the secretion of parathyroid hormone, resulting in increased bone resorption and subsequent bone loss. ${ }^{5-7}$ Therefore, nutritional management (ie, ensuring adequate calcium, vitamin $\mathrm{D}$, and vitamin $\mathrm{K}$ intakes) should play an important role in strengthening bone in athletes.

Physical function may be an important factor in avoiding poor performance and resulting injury in athletes. Vitamin D is known to play an important role in improving athletic performance in vitamin D-deficient athletes. ${ }^{8}$ It may be that physical function and vitamin D, and the evaluations of these, play a role in the reduction of sports-related injuries in athletes.

Very few reports have addressed injuries, including fractures, in Shorinji Kempo athletes. Furthermore, the strategy for prevention of fractures in Shorinji Kempo athletes remains to be established. The objectives of this study were to reveal the proportion of Shorinji Kempo athletes who had suffered fractures related to sports activities, and to evaluate bone mass, bone turnover, nutritional status, and physical function in these athletes.

\section{Subjects and methods Subjects}

Shorinji Kempo athletes who belonged to the Shorinji Kempo club of Keio University (Kanagawa, Japan) were studied. A medical checkup was carried out to investigate the proportion of athletes who had suffered fractures related to sports activities, and to evaluate the bone mass, bone turnover, nutritional status, and physical function of the athletes. All the examinations were performed at Hiyoshi Medical clinic
(Kanagawa, Japan) in February 2010. This study was conducted according to the guidelines laid down in the Declaration of Helsinki, and the study protocol was approved by the ethics committee of the Graduate School of Health Management, Keio University (Kanagawa, Japan). Written informed consent was obtained from all the participants.

\section{Anthropometry and history of injuries}

Height and body weight were measured, and the body mass index was calculated. Questionnaires were used to obtain information pertaining to the history of sports activities, and sports-related fractures.

\section{Bone mass}

A quantitative ultrasound (QUS) (CM-200; Furuno Electric Co, Ltd, Hyogo, Japan) was used to evaluate bone mass at the right calcaneus. QUS is a noninvasive, convenient method for evaluating bone, that provides information not only about the bone density, but also about bone architecture and elasticity. ${ }^{9}$ The speed of sound (SOS) as determined by QUS, was measured as an index of bone mass; and the percentage of the young adult mean (\%YAM) of SOS, was used for the analyses. Because no data existed for athletes $<20$ years old regarding the $\mathrm{Z}$ scores of SOS, we adopted the \%YAM as a $\mathrm{T}$ score, separately for males and females.

\section{Bone turnover}

Bone turnover was evaluated by measuring urinary levels of cross-linked N-terminal telopeptides of type 1 collagen (NTX). Urine samples were collected in the morning, and urinary NTX levels were quantified using an enzyme-linked immunosorbent assay (MOS-19; Mochida Pharmaceutical, Tokyo, Japan) using a specific monoclonal antibody.

Although the normal range of urinary NTX levels has been reportedly to be $9.3-54.3 \mathrm{nM} \mathrm{BCE} / \mathrm{mM} \mathrm{Cr}$ in premenopausal healthy Japanese women, ${ }^{10}$ standard urinary NTX levels for young athletes have not been established. A maturation-related reduction in urinary NTX levels has been reported with a steady state obtained after 18-20 years of age. ${ }^{11}$ Based on our previous study, ${ }^{11}$ the standard values for urinary NTX in athletes were determined using the following formula that accounts for age:

$$
\begin{aligned}
& \text { NTX }=5718.728-810.215 \times \text { age }+38.585 \times \mathrm{age}^{2} \\
& \quad-0.611 \times \mathrm{age}^{3}\left(\mathrm{r}^{2}=0.824\right)
\end{aligned}
$$

\section{Physical function}

Flexibility was evaluated using a bend and reach-performance test. Subjects were instructed to reach ahead as far as possible 
by bending the trunk and hip joints, while sitting on the floor with their knee joints extended. The distance that the subjects were able to reach was measured using a specific device (T-151; Toei Light Co, Saitama, Japan).

Body balance was evaluated by measuring the unipedalstanding time. Subjects stood on one leg for as long as possible with their eyes closed, keeping both arms close to their waist, and without use of an assistive device. This test was ended when the stance of the foot shifted, when the lifted foot touched the floor, when the subject's arms moved from the waist, or once $120 \mathrm{sec}$ had elapsed.

Muscle strength was evaluated by measuring the isometric extension and flexion strength of the right-knee joint, using a hand-held dynamometer ( $\mu$ Tas F-100; Anima Co, Tokyo, Japan). Measurements were taken while subjects assumed a sitting position, with the knee and hip joints flexed $90^{\circ}$, and a prone position with the knee joint flexed $90^{\circ}$.

Muscle power was evaluated by measuring the height of a vertical jump, and the rising-from-chair time. The vertical jump height was measured using a specific device (T-2290; Toei Light Co), while subjects were instructed to jump straight up as high as possible without any arm support; the chair-rising time was measured using a stopwatch, ${ }^{12,13}$ and was the time required for subjects to stand up from a chair (45 $\mathrm{cm}$ in height) ten times as quickly as possible, without the use of arms.

All of these physical function parameters were measured twice. The higher of the two results of the bend and reach distance, unipedal-standing time, isometric extension and flexion strength, and vertical jump height; and the lower results of the chair-rising time were adopted.

\section{Nutritional assessment}

A food frequency questionnaire for the prevention and management of osteoporosis developed by Uenishi et al, ${ }^{14}$ was used to evaluate nutritional status. The daily intakes of energy, protein, calcium, vitamin $\mathrm{D}$, and vitamin $\mathrm{K}$ were assessed. According to the dietary reference intakes in Japan, ${ }^{15}$ the recommended daily allowance (RDA) of protein is $50 \mathrm{~g}$ /day for women over the ages of 18 years, and $60 \mathrm{~g} /$ day for men over the ages of 12 years. According to the Japanese guidelines for the prevention and treatment of osteoporosis, ${ }^{2}$ the adequate intakes (AIs) of calcium, vitamin D and vitamin $\mathrm{K}$ are $800 \mathrm{mg} /$ day, $10-20 \mu \mathrm{g} /$ day, and 250-350 $\mu \mathrm{g} /$ day, respectively.

\section{Statistical analysis}

Data comparisons between male and female athletes were performed using the unpaired $t$-test. The proportion of athletes whose \%YAM of SOS was lower than 100, or whose urinary NTX level was higher than the standard values, was assessed. The proportion of athletes whose nutritional intakes were lower than the RDA or AI was assessed. \% YAM (T score) of SOS was compared between athletes with normal and higher levels of urinary NTX using the Mann-Whitney $U$ test. Correlations among the \%YAM of SOS, physical function, and nutritional status were examined by calculating the Pearson's correlation coefficient. Data were expressed as the means \pm standard deviation (SD). A significance level of $P<0.05$ was used for all the comparisons. All statistical analyses were performed using PASW Statistics (version 18.0; SPSS Inc, Chicago, IL) on a Windows computer.

\section{Results}

\section{Characteristics of study subjects}

Sixteen Shorinji Kempo collegiate athletes participated in the medical checkup. They were elite Japanese athletes who practice 4-6 days per week, and who participate in Shorinji Kempo competitions three times a year. Table 1 shows the characteristics of the study subjects.

Table I Characteristics of study subjects

\begin{tabular}{|c|c|c|c|c|}
\hline & All $(n=16)$ & Male $(n=12)$ & Female $(n=4)$ & $P$ value \\
\hline Age (years) & $20.5 \pm 1.1$ & $2 I . I \pm 1 . I$ & $20.3 \pm 0.8$ & NS \\
\hline Height $(\mathrm{cm})$ & $165.4 \pm 9.9$ & $170.1 \pm 6.0$ & $|5| .5 \pm 4.0$ & $<0.00$ I \\
\hline Body weight (kg) & $57.6 \pm 9.3$ & $61.3 \pm 7.5$ & $46.3 \pm 2.4$ & $<0.01$ \\
\hline Body mass index $\left(\mathrm{kg} / \mathrm{m}^{2}\right)$ & $20.9 \pm 1.7$ & $21.2 \pm 1.9$ & $20.2 \pm 1.0$ & NS \\
\hline Weight-bearing sports experience (yes/no) & $13 / 3$ & $10 / 2$ & $3 / 1$ & \\
\hline Elementary school (yes/no) & $6 / 10$ & $5 / 7$ & $1 / 3$ & \\
\hline Junior high school (yes/no) & $\mathrm{I} \mid / 5$ & $8 / 4$ & $3 / 1$ & \\
\hline High school (yes/no) & $9 / 7$ & $6 / 6$ & $3 / 1$ & \\
\hline Shorinji Kempo experience (years) & $3.0 \pm 2.1$ & $3.4 \pm 2.3$ & $1.8 \pm 1.0$ & NS \\
\hline
\end{tabular}

Notes: Data were expressed as the means \pm SD. Data comparisons between male and female athletes were performed using the unpaired $t$-test. Abbreviation: NS, not significant. 
Table 2 Fractures related to Shorinji Kempo activity

\begin{tabular}{llll}
\hline & $\begin{array}{l}\text { All } \\
(\mathbf{n}=16)\end{array}$ & $\begin{array}{l}\text { Male } \\
(\mathbf{n}=12)\end{array}$ & $\begin{array}{l}\text { Female } \\
(\mathbf{n}=\mathbf{4})\end{array}$ \\
\hline $\begin{array}{l}\text { History of traumatic fracture } \\
\text { related Shorinji Kempo }\end{array}$ & $7 / 9$ & $5 / 7$ & $2 / 2$ \\
$\begin{array}{l}\text { activity (yes/no) } \\
\text { Finger }\end{array}$ & & \\
Toe & 2 & 2 & 0 \\
Rib & 2 & $\mathrm{I}$ & $\mathrm{I}$ \\
Tibia & 2 & 2 & 0 \\
\hline
\end{tabular}

\section{Fractures related to Shorinji} Kempo activity

Table 2 shows bone fractures related to Shorinji Kempo activity. Seven athletes (43.8\%) had a history of a fracture related to Shorinji Kempo activity. The sites of fracture were the finger $(n=2)$, toe $(n=2)$, ribs $(n=2)$, and tibia $(\mathrm{n}=1)$.

\section{SOS and urinary NTX}

Table 3 summarizes the SOS and urinary NTX measurements. The mean SOS was $1547.3 \mathrm{~m} / \mathrm{sec}$, which corresponded to $105.3 \%$ of the YAM. The mean urinary NTX level was $82.7 \mathrm{nM} \mathrm{BCE} / \mathrm{mM}$ Cr. Five athletes (31.3\%) had higher levels of urinary NTX than the age-adjusted standard values, which were calculated using the formula shown above. The $\%$ YAM of SOS in the athletes with higher levels of urinary NTX was significantly lower than in those with normal levels $(93.2 \% \pm 22.6 \%$ versus $110.8 \% \pm 11.4 \%$, respectively, $P<0.05$ ) (Figure 1).

\section{Physical function}

Table 4 summarizes the results of the tests of physical function. The mean bend-reach distance was $39.6 \mathrm{~cm}$, and the mean unipedal-standing time was $61.2 \mathrm{sec}$. The mean measures of isometric-knee extensor and flexor muscle strength were $0.65 \mathrm{~kg} /$ body weight and $0.25 \mathrm{~kg} /$ body weight, respectively. The mean vertical jump height was $43.7 \mathrm{~cm}$, and the mean chair-rising time was $9.93 \mathrm{sec}$.

\section{Nutritional status}

Table 5 shows the daily energy and nutritional intakes. The mean daily energy intake was $1892.4 \mathrm{kcal}$. The mean daily intakes of protein, calcium, vitamin $\mathrm{D}$, and vitamin $\mathrm{K}$ were $78.0 \mathrm{~g}, 391.1 \mathrm{mg}, 7.8 \mu \mathrm{g}$, and $149.5 \mu \mathrm{g}$, respectively.

Of the 16 athletes, four (25\%) had a lower daily protein intake than the RDA ( $60 \mathrm{~g} /$ day for males, and $50 \mathrm{~g} /$ day for females). All the athletes had a lower daily calcium intake than the AI $(800 \mathrm{mg} /$ day $)$. Twelve athletes $(75.0 \%)$ had a lower daily vitamin D intake than the AI (10-20 $\mu \mathrm{g}$ /day). Fifteen athletes $(93.8 \%)$ had a lower daily vitamin $\mathrm{K}$ intake than the AI (250-300 $\mu \mathrm{g} /$ day).

\section{Correlations among the \%YAM of the SOS, physical function, and nutritional status}

No significant correlations were found between the \%YAM (T score) of the SOS and the physical function parameters, nor between the \%YAM of the SOS and the daily energy, calcium, vitamin $\mathrm{D}$, and vitamin $\mathrm{K}$ intakes. However, significant positive correlations were found between the vertical jump height, and the daily energy and protein intakes ( $\mathrm{r}=0.570, P<0.05$; and $\mathrm{r}=0.520, P<0.05$, respectively) (Figure 2). Notwithstanding these significant correlations, no significant correlations were found between the physical function parameters and the daily energy, calcium, vitamin $\mathrm{D}$, and vitamin $\mathrm{K}$ intakes.

\section{Discussion}

The present study revealed that as many as $43.8 \%$ of the Shorinji Kempo athletes had a history of a fracture during Shorinji Kempo practice, and that some Shorinji Kempo athletes had a low SOS, higher levels of urinary NTX, and lower daily calcium, vitamin $\mathrm{D}$, and vitamin $\mathrm{K}$ intakes. These results suggest that fractures are common among Shorinji Kempo athletes, and that some Shorinji Kempo athletes need to improve their bone mass, bone metabolism, and nutritional status in order to strengthen bone and improve physical function.

Table 3 SOS and urinary NTX

\begin{tabular}{lcccc}
\hline & All $(\mathbf{n}=1 \mathbf{1 6})$ & Male $(\mathbf{n}=1 \mathbf{2})$ & Female $(\mathbf{n}=\mathbf{4})$ & P value \\
\hline SOS $(\mathrm{m} / \mathrm{sec})$ & $1547.3 \pm 31.4$ & $1537.5 \pm 27.6$ & $1576.8 \pm 24.0$ & $<0.05$ \\
\%YAM (T score) & $105.3 \pm 17.2$ & $99.9 \pm 15.0$ & $121.5 \pm 6.7$ & $<0.05$ \\
Urinary NTX (mM BCE/mM Cr) & $82.7 \pm 59.1$ & $93.8 \pm 64.9$ & $49.4 \pm 6.7$ & $<0.05$ \\
\hline
\end{tabular}

Notes: Data were expressed as the means \pm SD. Data comparisons between male and female athletes were performed using the unpaired $t$-test.

Abbreviations: SOS, speed of sound; NTX, cross-linked N-terminal telopeptides of type I collagen; YAM, young adult mean. 


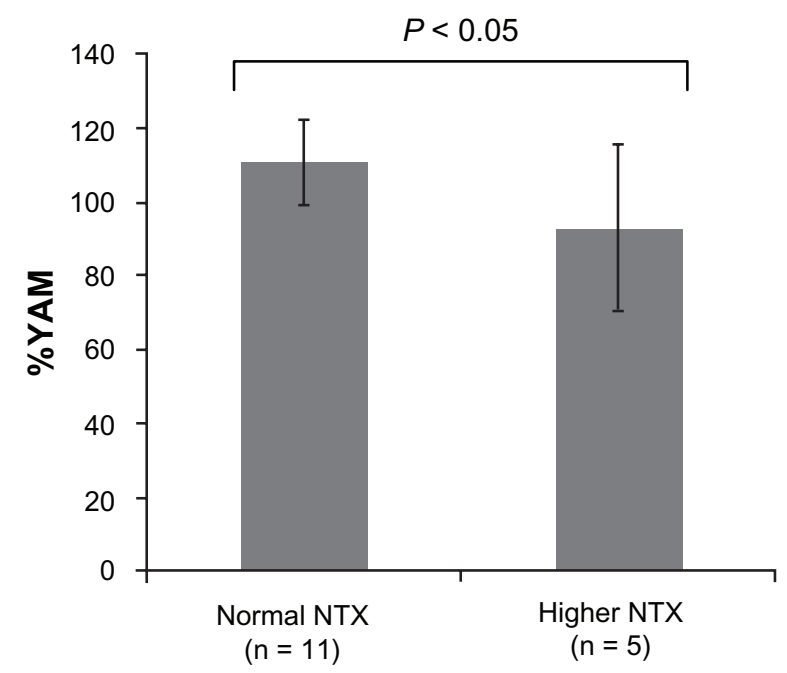

Figure I \%YAM of SOS and urinary NTX.

Abbreviations: YAM, young adult mean; SOS, speed of sound; NTX, cross-linked $\mathrm{N}$-terminal telopeptides of type I collagen.

Bone mineral density measured by dual-energy X-ray absorptiometry (DXA) remains the optimal method for evaluating bone mass. QUS is a more recently developed noninvasive method to study bone density and structure in-vivo. A linear regression has been reported between the QUS parameters of the calcaneus, and the bone mineral density of the lumbar spine $(r=0.486)$ and hip $(r=0.501)$, as measured using DXA. ${ }^{16}$ It has further been shown that QUS parameters can predict the risk of development of hip, wrist, and total nonvertebral fractures, for up to 10 years. ${ }^{17}$ Indeed, it may be possible to better account for structural changes of the bone by means of QUS, than by the conventional DXA method. ${ }^{18}$ Because QUS is a noninvasive, and convenient method for evaluating bone, we utilized this method in our medical assessment of young athletes.

Shorinji Kempo is a combat sport, with contusive movements at its very core. Therefore, injuries and fractures are predictactable. In the present study, of sixteen athletes, seven $(43.8 \%)$ had a history of a fracture related to a Shorinji
Kempo activity. Critchley et al. ${ }^{1}$ previously reported the injury rates in 1273 Shotokan Karate athletes. In that study, 160 injuries were recorded in 1770 bouts, giving an incidence of one injury in 11 bouts, or 0.09 injuries per bout, and 0.13 injuries per competitor. Five $(3.1 \%)$ face fractures and five $(3.1 \%)$ limb fractures or dislocations were observed. The incidence of fractures was considered to be high in Shorinji Kempo athletes.

This high incidence might be attributable to the natural course of accidents during the practice. However, a metaanalysis study has shown that there is an association between low bone density and fractures, in children. ${ }^{19}$ Several studies have reported that fractures occurring during youth might be associated with a reduction in bone gain during puberty, and it might be associated with subsequent low-peak bone mass, ${ }^{20}$ genetic factors, ${ }^{21}$ and physical inactivity, and muscle, loss secondary to fractures. ${ }^{22}$ It is likely that the greater bone strength (mainly determined by bone mass) is, the lower is the incidence of fractures during practice. Thus, maintenance of bone mass is important to sustain bone health in Shorinji Kempo athletes, who are prone to developing fractures during practice.

In the present study, the \%YAM of the SOS in athletes with elevated levels of urinary NTX was significantly lower than in athletes with normal levels of urinary NTX; because of this, high bone turnover might have contributed to the low bone mass. Consequently, countermeasures to low bone mass and high bone turnover are needed for Shorinji Kempo athletes who have experienced fractures during their youth.

Positive correlations were found between one of the indices of muscle power, the vertical-jump height, and the daily energy and protein intakes. Protein plays an important role in the recovery of muscle damage arising from training, as well as from muscle fiber hypertrophy, ${ }^{23}$ and consequently contributes to an improvement in physical performance. ${ }^{24,25}$ Our results support the suggestion that protein intake may

Table 4 Physical function

\begin{tabular}{|c|c|c|c|c|}
\hline & All $(n=16)$ & Male $(n=12)$ & Female $(n=4)$ & $P$ value \\
\hline Bend reach distance $(\mathrm{cm})$ & $39.6 \pm 11.0$ & $39.5 \pm 10.5$ & $39.8 \pm 15.5$ & NS \\
\hline Unipedal standing time (sec) & $61.2 \pm 37.8$ & $58.8 \pm 35.7$ & $68.7 \pm 48.8$ & NS \\
\hline \multicolumn{5}{|c|}{ Muscle strength (kg/body weight) } \\
\hline Knee extensor & $0.65 \pm 0.11$ & $0.64 \pm 0.11$ & $0.60 \pm 0.15$ & NS \\
\hline Knee flexor & $0.25 \pm 0.06$ & $0.25 \pm 0.06$ & $0.23 \pm 0.05$ & NS \\
\hline Jump height $(\mathrm{cm})$ & $43.7 \pm 9.0$ & $47.3 \pm 7.2$ & $33.8 \pm 5.1$ & $<0.01$ \\
\hline Chair rising time (sec) & $9.93 \pm 1.84$ & $9.9 \pm 1.9$ & $10.2 \pm 1.9$ & NS \\
\hline
\end{tabular}

Notes: Data were expressed as the means \pm SD. Data comparisons between male and female athletes were performed using the unpaired $t$-test.

Abbreviation: NS, not significant. 
Table 5 Daily energy and nutritional intakes

\begin{tabular}{lcccc}
\hline & All $(\mathbf{n}=\mathbf{I 6})$ & Male $(\mathbf{n}=\mathbf{I 2})$ & Female $(\mathbf{n}=\mathbf{4})$ & \\
\hline Energy $(\mathrm{kcal})$ & $1892.4 \pm 429.0$ & $2021.4 \pm 344.7$ & $1505.3 \pm 466.8$ & \\
Protein $(\mathrm{g})$ & $78.0 \pm 21.0$ & $82.9 \pm 18.9$ & $63.3 \pm 22.3$ & $\mathrm{~N}$ value \\
Calcium (mg) & $391.1 \pm 161.3$ & $400.3 \pm 166.0$ & $363.8 \pm 166.4$ & $\mathrm{NS}$ \\
Vitamin D (mcg) & $7.8 \pm 3.1$ & $8.2 \pm 3.3$ & $6.5 \pm 2.3$ & $\mathrm{NS}$ \\
Vitamin K (mcg) & $149.5 \pm 105.3$ & $155.7 \pm 112.5$ & $131.0 \pm 91.9$ & $\mathrm{NS}$ \\
\hline
\end{tabular}

Notes: Data were expressed as the means \pm SD. Data comparisons between male and female athletes were performed using the unpaired $t$-test. The RDA of protein is $50 \mathrm{~g} /$ day for women over 18 years old, and $60 \mathrm{~g} /$ day for men over 12 years old. The Als of calcium, vitamin D, and vitamin K are $800 \mathrm{mg} / \mathrm{day}, \mathrm{I} 0-20 \mu \mathrm{g} / \mathrm{day}$, and $250-350 \mu \mathrm{g} / \mathrm{day}$, respectively.

Abbreviations: NS, not significant; RDA, recommended daily allowance; Als, adequate intakes.

be correlated with physical function. Of the 16 athletes, four $(25 \%)$ had a lower daily protein intake than the RDA; these athletes should improve their daily protein intake in order to improve their physical function.

In our study, the mean daily intake of protein was $78.0 \mathrm{~g}$, which exceeds the RDA of protein (50-60 g/day), according to Japanese dietary standards. ${ }^{15}$ However, it is recommended that strength- or speed-building athletes take in $1.2-1.7 \mathrm{~g}$ of protein per kg body weight per day, ${ }^{26}$ or, given that the mean body weight of subjects was $57.6 \mathrm{~kg}, 69.1-97.9 \mathrm{~g}$ of protein per day. Thus, the actual protein intake of our subjects was within the standard range. It is likely that an increased daily intake of protein may play a role in improving physical performance. There are five levels of "dan" [1 st dan (Jun-kenshi), 2nd dan (Sho-kenshi), 3rd dan (Chu-kenshi), 4th dan (Sei-kenshi), and 5th dan (Dai-kenshi)] to be achieved in Shorinji Kempo. Each level of dan has requirements for body and spiritual training that must be attained in order to advance to the next level, but none of these involve weight, and there was no need for weight control in these athletes. Conversely, it is likely that an increased daily intake of protein may play a role in mastery of level skills in Shorinji Kempo athletes.

Athletes' daily intakes of calcium, vitamin $\mathrm{D}$, and vitamin $\mathrm{K}$ were lower than the recommended AIs (in 100\%, 75.0\%,
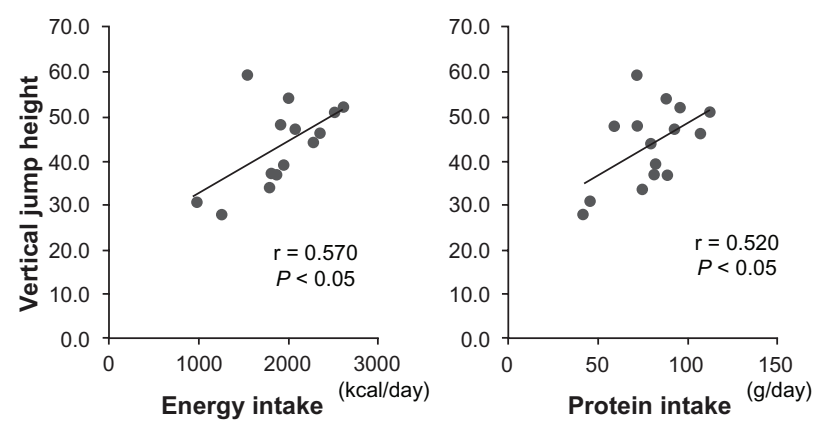

Figure $\mathbf{2}$ Correlations between vertical jump height and energy and protein intakes. Note: Significant positive correlations were found between vertical jump height, and daily energy and protein intakes $(r=0.570, P=0.0026$ and $r=0.520, P=0.047$, respectively) by the Pearson's correlation coefficient. and $93.8 \%$ of cases, respectively), thus nutritional status related to these key bone and physical function nutrients was poor in most of the Shorinji Kempo athletes. A meta-analysis has previously shown that youth is an important period for gaining bone mass through the ingestion of calcium. ${ }^{27}$ It has also been shown that Vitamin D deficiency results in hyperparathyroidism and subsequent loss of bone from increased bone resorption..$^{5-7}$

Conversely, vitamin D and calcium supplementation has been demonstrated to reduce the risk of stress fractures in female Navy recruits. ${ }^{28}$ In one study, vitamin D also played an important role in improving athletic performance in vitamin D-deficient athletes. ${ }^{8}$ Vitamin $\mathrm{K}$ has also been shown to improve bone quality and to reduce the risk of fractures. ${ }^{29}$ Thus, calcium, vitamin D, and vitamin K play an important role in gaining bone mass and possibly in preventing fractures in athletes. Following from this, some of the Shorinji Kempo athletes needed to improve their bone mass, bone metabolism, and nutritional status to strengthen bone and improve physical function.

There are notable limitations in the present study. First, a control group was not included in the present study, despite the fact that standards for the evaluated physical functions have not been established in young athletes and nonathletes. Second, although we recruited all members of the Shorinji Kempo club of Keio University, the sample size was small and may have affected correlations among the \%YAM (T score) of SOS, physical function, and nutritional status. Third, bone mass was evaluated using a QUS device, as opposed to the conventional measurement by DXA. The bone mineral density of the lumbar spine and hip continues to be important in anticipating fracture risk, even though a linear regression has been reported between QUS parameters of the calcaneus, and the bone mineral density of the lumbar spine and hip as measured by DXA. ${ }^{16}$ Thus, further studies with a large number of subjects including a control group are needed to confirm our results. 


\section{Conclusion}

A medical checkup was carried out for Shorinji Kempo college athletes to investigate the proportion of athletes who had suffered fractures during practice, and to evaluate bone mass, bone turnover, nutritional status, and physical function. The results of the medical examinations suggest that fractures are a common injury among Shorinji Kempo athletes, and some Shorinji Kempo athletes should improve their bone mass, bone metabolism, and nutritional status in order to strengthen bone and improve their physical function.

\section{Acknowledgments}

We would like to thank Dr Kazuhiro Uenishi of the Laboratory of Physiological Nutrition, Kagawa Nutrition University (Saitama, Japan) for evaluating nutritional status. We would also like to thank the students of the Graduate School of Health Management, Keio University (Kanagawa, Japan), and the nurses in the Hiyoshi Medical Clinic (Kanagawa, Japan), for providing assistance during the medical examinations.

\section{Disclosure}

The authors report no financial or other conflicts of interest in this work.

\section{References}

1. Critchley GR, Mannion S, Meredith C. Injury rates in Shotokan karate. Br J Sports Med. 1999;33(3):174-177.

2. Orimo H, editor. Japanese Guidelines for the Prevention and Treatment of Osteoporosis. Tokyo, Japan: Life Sciences Publishing; 2006.

3. Vergnaud P, Garnero P, Meunier PJ, Bréart G, Kamihagi K, Delmas PD. Undercarboxylated osteocalcin measured with a specific immunoassay predicts hip fracture in elderly women: the EPIDOS Study. $J$ Clin Endocrinol Metab. 1997;82(3):719-724.

4. Tsugawa N, Shiraki M, Suhara Y, et al. Low plasma phylloquinone concentration is associated with high incidence of vertebral fracture in Japanese women. J Bone Miner Metab. 2008;26(1):79-85.

5. Sahota O. Osteoporosis and the role of vitamin $\mathrm{D}$ and calcium-vitamin $\mathrm{D}$ deficiency, vitamin D insufficiency and vitamin D sufficiency. Age Ageing. 2000;29(4):301-304.

6. Chapuy MC, Preziosi P, Maamer M, et al. Prevalence of vitamin D insufficiency in an adult normal population. Osteoporos Int. 1997;7(5): 439-443.

7. Jesudason D, Need AG, Horowitz M, O'Loughlin PD, Morris HA, Nordin BE. Relationship between serum 25-hydroxyvitamin D and bone resorption markers in vitamin D insufficiency. Bone. 2002;31(5):626-630.

8. Cannell JJ, Hollis BW, Sorenson MB, Taft TN, Anderson JJ. Athletic performance and vitamin D. Med Sci Sports Exerc. 2009;41(5): $1102-1110$.

9. Hans D, Dargent-Molina P, Schott AM, et al. Ultrasonographic heel measurements to predict hip fracture in elderly women: the EPIDOS prospective study. Lancet. 1996;348(9026):511-514.

10. Nishizawa $\mathrm{Y}$, Nakamura $\mathrm{T}$, Ohta $\mathrm{H}$, et al; for Committee on the Guidelines for the Use of Biochemical Markers of Bone Turnover in Osteoporosis Japan Osteoporosis Society. Guidelines for the use of biochemical markers of bone turnover in osteoporosis (2004). $J$ Bone Miner Metab. 2005;23(2):97-104.
11. Iwamoto J, Takeda T, Matsumoto H. Urinary levels of cross-linked $\mathrm{N}$-terminal telopeptides of type I collagen are higher in athletes with a symptomatic stress fracture. Jpn J Orthop Sports Med. 2009; 29:54-60.

12. Runge M, Rehfeld GM, Resnicek E. Balance training and exercise in geriatric patients. $J$ Musculoskelet Neuronal Interact. 2000;1(1): 61-65.

13. Runge M, Hunter G. Determinants of musculoskeletal frailty and the risk of falls in old age. $J$ Musculoskelet Neuronal Interact. 2006;6(2): 167-173.

14. Uenishi K, Ishida H, Nakamura K. Development of a simple food frequency questionnaire to estimate intakes of calcium and other nutrients for the prevention and management of osteoporosis. J Nutr Sci Vitaminol (Tokyo). 2008;54(1):25-29.

15. Sasaki S. Dietary Reference Intakes (DRIs) in Japan. Asia Pac J Clin Nutr. 2008;17 Suppl 2:S420-S444.

16. Faulkner KG, McClung MR, Coleman LJ, Kingston-Sandahl E. Quantitative ultrasound of the heel: correlation with densitometric measurements at different skeletal sites. Osteoporos Int. 1994;4(1):42-47.

17. Fujiwara S, Sone T, Yamazaki K, et al. Heel bone ultrasound predicts non-spine fracture in Japanese men and women. Osteoporos Int. 2005;16(12):2107-2112.

18. Wüster C, Heilmann P, Pereira-Lima J, Schlegel J, Anstätt K, Soballa T. Quantitative ultrasonometry (QUS) for the evaluation of osteoporosis risk: reference data for various measurement sites, limitations and application possibilities. Exp Clin Endocrinol Diabetes. 1998;106(4):277-288.

19. Clark EM, Tobias JH, Ness AR. Association between bone density and fractures in children: a systematic review and meta-analysis. Pediatrics. 2006; 117(2):e291-e297.

20. Ferrari SL, Chevalley T, Bonjour JP, Rizzoli R. Childhood fractures are associated with decreased bone mass gain during puberty: an early marker of persistent bone fragility? J Bone Miner Res. 2006;21(4):501-507.

21. Ferrari S, Rizzoli R, Slosman D, Bonjour JP. Familial resemblance for bone mineral mass is expressed before puberty. J Clin Endocrinol Metab. 1998;8(2)3:358-361.

22. Popp KL, Hughes JM, Smock AJ, et al. Bone geometry, strength, and muscle size in runners with a history of stress fracture. Med Sci Sports Exerc. 2009;41(12):2145-2150.

23. Tipton KD, Elliott TA, Cree MG, Aarsland AP, Sanford AP, Wolfe RR. Stimulation of net muscle protein synthesis by whey protein ingestion before and after exercise. Am J Physiol Endocrinol Metab. 2007;292(1):E71-E76.

24. van Essen M, Gibala MJ. Failure of protein to improve time trial performance when added to a sports drink. Med Sci Sports Exerc. 2006; 38(8):1476-1483.

25. Hoffman JR, Ratamess NA, Tranchina CP, Rashti SL, Kang J, Faigenbaum AD. Effect of protein-supplement timing on strength, power, and body-composition changes in resistance-trained men. Int $J$ Sport Nutr Exerc Metab. 2009;19(2):172-185.

26. Lemon PW. Effect of exercise on protein requirements. J Sports Sci. 1991;9 Suppl:S53-S70.

27. Welten DC, Kemper HC, Post GB, van Staveren WA. A meta-analysis of the effect of calcium intake on bone mass in young and middle aged females and males. J Nutr. 1995;125(11):2802-2813.

28. Lappe J, Cullen D, Haynatzki G, Recker R, Ahlf R, Thompson K. Calcium and vitamin $\mathrm{d}$ supplementation decreases incidence of stress fractures in female navy recruits. J Bone Miner Res. 2008;23(5): 741-749.

29. Shiraki M, Shiraki Y, Aoki C, Miura M. Vitamin K2 (menatetrenone) effectively prevents fractures and sustains lumbar bone mineral density in osteoporosis. J Bone Miner Res. 2000;15(3):515-521. 


\section{Publish your work in this journal}

Open Access Journal of Sports Medicine is an international, Visit http://www.dovepress.com/testimonials.php to read real quotes peer-reviewed, open access journal publishing original research, from published authors.

reports, reviews and commentaries on all areas of sports

medicine. The manuscript management system is completely

online and includes a very quick and fair peer-review system.

Submit your manuscript here: http://www.dovepress.com/open-access-journal-of-sports-medicine-journal 